\title{
Bottlenecks in the provision of quality mental health services in Eritrea.
}

\author{
Yohannes Ghebrat (MD)1, Goitom Mebrahtu (MD)2, Andrew Kosia (MD)1, \\ Jako Mufunda (MD)1, A. Usman (MD)1, Jerom Oomen (MD)3, \\ Institutional affiliation: \\ 1 WHO Eritrea Country Office Asmara \\ 2 Ministry of Health of the State of Eritrea \\ 3 TPO, Asmara, Eritrea
}

Corresponding author: Dr. Yohannes Ghebrat WHO Eritrea Country Office PO Box 5561， Asmara, Eritrea Telephone: 291-1-114171; 114167; 115350 Fax: 291-1-125155_Email: ghebraty@er.afro.who.int

\section{Abstract}

Background: The prevalence of mental disorders is increasing significantly in developing countries due to the frequently occurring major risk factors. There is no published information on the profile of mental health disorder and services in Eritrea.

Objective of the study: Follow-up descriptive study was conducted on one hundred and one consecutive children with advanced HIV disease who were put on antiretroviral therapy from September 2005 to October 2006. These patients were followed up at the antiretroviral therapy (ART) clinic of the hospital.

Methods: A descriptive cross sectional study was conducted using the WHO-AIMS questionnaire that was administered to relevant stakeholders.

Results: There was no comprehensive mental health policy and legislation in Eritrea. Only $5 \%$ of the health services budget is allocated for mental health services. Mental health services is free of charge and were provided integrated with Primary Health Care services. Inadequate human resources and inadequate training on mental health for the health workers were among the constraints.

Conclusion: The status of mental disorders and the mental health services in Eritrea from the policy to management guidelines requires urgent review.

Significant Outcomes: a) In resource limited settings, the integrated primary health care approach for mental health services is cost effective and avoids associated stigma.

b) WHO/AIMS tool is a simple tool that provides complete picture of the mental health system of a country,

c) Lack of policies and legislation in a country severely affects the mental health system of a country

Limitations: This was a cross sectional study where data collection and analysis was partially restricted by the level and quality of information available in the registry books of the health facilities.

Key words: WHO-AIMS, integrated primary health care, mental health services,

\section{Introduction:}

Mental health is described by World Health Organization as a state of well being in which the individual realizes his or her own abilities, can cope with the normal stresses of life, can work productively and fruitfully, and is able to make a contribution to his or her community 1. Public health approaches that include health promotion, prevention of illness and disability, and the treatment and rehabilitation of those affected, are the key means that can improve mental health and lower the personal and social costs of mental ill health. WHO advocates for the integration of mental health services approach within the framework of primary health care in order to provide holistic health care to the community 2.

Although mental health services had made significant improvement in the developed countries, it is not so in the developing countries. Most countries in the developed world have clearly established policies and legislations, have significant number of documented mental health research publications, adequate well trained human resource, specialized health facility and community based mental health services 3. Consequently, the outcome of mental health services is much better than the developing countries.

Mental disorders account for $11.1 \%$ of the disease burden in the Low and Middle Income Countries (LAMIC)4. This is expected to increase to $15 \%$ by 2020. Study conducted by WHO internationally, showed that about $25 \%$ of all attendees in PHC setting were suffering from mental disorders mainly depression and anxiety 5 . These disorders are also associated with significant level of disability 6, as reported in India 7 and Africa 8. However, there is severe shortage of mental health services especially in the developing countries 9,10 and particularly in Sub-Saharan Africa 11.

The major risk factors that determine the vulnerability of people to mental health disorders include: poverty, insecurity and hopelessness, rapid social change, the risks of violence and physical ill health 12 .

Eritrea passed through a 30 year period of armed struggle for independence. It was liberated in 1991 and became officially independent in 1993 through a referendum. The protracted war left significant psychological trauma though there is little published information on this 13. In general, war, disasters and civil violence are major risk factors for mental disorders 14 
world wide.

The objective of this study was to determine the prevailing mental disorders and health services in Eritrea so as to update policies and policy guidelines on this rapidly changing medical field.

\section{Materials and Methods}

This is a descriptive cross sectional study conducted nationwide during the period from 31 October to 30th November 2005 covering all the 6 Zones in Eritrea using WHO/AIMS questionnaire. WHO-AIMS is a tool developed to collect information on the mental health system of a country or region in order to promote, restore or maintain mental health services. It comprises of 6 domains which are interlinked and interdependent to provide a complete picture of the mental health system of low and middle income countries (LAMIC). The domains include: Policy and legislative framework, mental health services, mental health in primary health care, human resources, public education and links with other sectors, and monitoring and research.

Two questionnaires were used for the study: one to assess policy services and legislation which was administered to the Ministries of Health, Justice, and that of Labour and Human Welfare and the other questionnaire to assess the organization of mental health services was administered to the 6 Zones.

Data collection was conducted at the national, Zonal and health facility levels. Assessment of mental health services was conducted in all 6 Zones, in the only Mental Hospital in the country, 14 Zonal Hospitals, 1 Community Residential Facility and 30 Primary Health Care facilities.

The data collected was entered into the WHOAIMS excel entry program and was analyzed on the basis of indicators of various domains: mental health expenditure rate, organization of mental health services, proportion of patients treated in mental health facilities and proportion of human resource in mental health care.

\section{Results}

With respect to policy and legislative framework, the study found that there was no separate self standing mental health policy in Eritrea. However, the Primary Health Care policy had a component on mental health which focused on the development of mental health structures as well as general strategies. This component on mental health policy endorsed the utilization of certain essential psychotropic drugs such as antipsychotics, anxiolytics, antidepressant, mood stabilizers and anti-epileptics. There was no comprehensive mental health plan or mental health legislation in the country.

The study found that there was only one mental hospital in the country with a total of 160 beds (4.44 per 100,000 people), with no facility dedicated for children and adolescents with mental illnesses.

Mixtures of hospital and residential facility based services were provided for the care of mentally ill patients in the country. The existing mental hospital had 966 inpatient admissions and 2,700 outpatient services in 2004.

\section{Figure 1}



More than $60 \%$ of the patients with mental disorders were males with the remaining $40 \%$ being females. Children and/or adolescents made up of about $1 \%$. $36 \%$ of admissions to the mental hospital were involuntary. Over $20 \%$ of patients were physically restrained or secluded at least once in the previous year in the mental hospital.

On average, patients spent 48.4 days in the mental hospital and about three quarters (74\%) of patients spent less than one year in the hospital.

In 2004, mental disorders reported at the hospital and health centers accounted for $0.49 \%$ of the entire disease burden. The most frequent primary diagnosis of the inpatients in the mental hospital was schizophrenia representing one third followed by personality disorders. The least prevalent was neurotic disorders and substance abuse (Table 1).

Table 1: Patients Treated in Mental Health Facilities By Diagnosis

\begin{tabular}{l|c|c|}
\multicolumn{1}{|c|}{ Diagnosis } & Mental Hospital & $\begin{array}{c}\text { Outpatient } \\
\text { Facility }\end{array}$ \\
\hline $\begin{array}{l}\text { Schizophrenia } \\
\begin{array}{l}\text { Personality } \\
\text { Disorder }\end{array}\end{array}$ & $32 \%$ & $11 \%$ \\
\hline $\begin{array}{l}\text { Mood Disorder } \\
\text { Neurotic }\end{array}$ & $25 \%$ & $15 \%$ \\
$\begin{array}{l}\text { Disorder } \\
\text { Substance }\end{array}$ & $21 \%$ & $17 \%$ \\
\hline $\begin{array}{l}\text { Abuse } \\
\text { Others }\end{array}$ & $2 \%$ & $22 \%$ \\
\hline
\end{tabular}

There was only one community residential facility in the country with 150 beds (4.2 per 100,000). Only one bed is reserved for patients under 18 years of age. The Community Residential Facility treated 79 cases in 2004 of which $50.6 \%$ were females.

All Hospitals and Mini-Hospitals providing mental 
health services were managed by a physician whereas health centers and health stations were run by nurses and associate nurses respectively. The major bottlenecks in cost effective service provision were a critical shortage of human resource capacity and inadequate integration of the mental health services into the primary health care system. In the pre-service training of doctors and nurses, only about $1 \%$ and $4 \%$ of the whole training was devoted to mental health course respectively. In addition, the refresher courses on mental health disease management were inadequately administered to health workers.

Based on the assessment conducted, the total number of health workers providing mental health services in the country was 0.83 per 100,000 people. These were 2 psychiatrists, 2 medical doctors not specialized in psychiatry, 12 nurses trained in psychiatry and 1 psychologist. There was no psychiatrist assigned outside of the capital city.

Figure 2

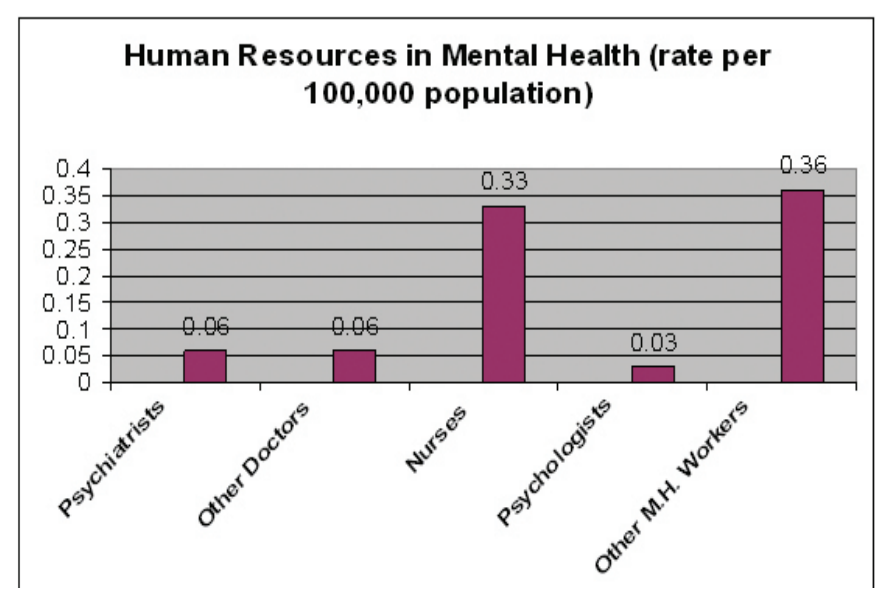

Only $5 \%$ out of the total health expenditure was allocated for mental health services of which $93 \%$ was dedicated for the existing mental hospital in Asmara. All therapeutic categories of drugs were available in the hospital and mental health service was provided free of charge including disbursement of psychotropic drugs. There were inadequate supplies of psychotropic medicines in the country with less than $20 \%$ of the Physician-based primary health care clinics had stocks of at least one psychotropic medicine of each therapeutic category.

Mental health service is provided as part of the routine general services integrated with in the health services but not in a specialized mental health unit within the health facility. Psychotropic drugs are prescribed by physicians only but not by a non doctor/ non-nurse PHC workers unless they are in a facility without a physician.

\section{Discussion}

A descriptive cross sectional survey was conducted using WHO-AIMS tool that provides a comprehensive picture of mental health services in Eritrea 15 in order to review policies and guidelines. The main findings of this assessment include limited mental health facilities with shortages of human resources, drugs and no facilities dedicated to children and adolescents. There was weak integration of mental health services within the primary health care services. Schizophrenia and personality disorders were the two most frequent diagnoses among the inpatients.

The $\mathrm{MOH}$ introduced primary health care as the guiding policy in 1993 to direct all health interventions including mental health services. This PHC policy was revised in 1998 and had all disciplines 16. The mental health policy component did not give detailed directions in terms of financing, legislation and human rights, organization of services, human resources, essential drug procurement and distribution, quality improvement, research and information system, which are principal areas for action 17. Moreover, the policy did not have detailed and comprehensive implementation framework.

The absence of a separate mental health policy and supportive legislative framework is not unique to Eritrea as more than $30 \%$ of all countries share the same predicament leaving patients with mental disorders with no legal protection 3. In addition, health facilities for mental health services are limited to one hospital dedicated to providing these services with no separate facilities for children and adolescents. This situation can be explained by the fact that Eritrea is a new nation coming out of a long protracted conflict with many priorities competing for limited resources.

The major bottleneck in the provision of quality mental health services is the shortage of experienced psychiatrists due to lack of local production. This is similar to most countries in Africa where the average psychiatrist-population ratio is 0.05 per 100,000 . In developed countries this ratio reaches nearly 180 times that of the developing ones 18 ; that is for every 1 psychiatrist in the developing country, there are 180 psychiatrists in the developed world. In addition, the physicians and other health workers who provide the services receive sub-optimal refresher training in mental health care. In other developing countries this problem has been mitigated by local training but offset by brain drain, a situation which is being addressed at a global level 19. As a result, the level of mental health services is limited.

The huge burden of mental health problems in developing countries, the meager resources available for mental health services and the acute shortage of trained health personnel, would necessitate for the need of a comprehensive integration of mental health services with in the primary health care as recommended by WHO20. Many developing countries have recognized the draw backs of the vertical mental health services and introduced an integrated approach of the mental health services into the PHC 20, 21, 22. Additional back up through provision of an intense training course for Health Workers on basic and clinical psychiatry for easy recognition and management of common mental health problems and appropriate referrals 23 was also recommended. Although the integration component is evident in the Eritrean setting, there is no intense refresher training courses for health workers, a situation which is similar to many 
other developing countries. This could possibly be to the low level of priority given to mental health service in the country.

In our setting, the low prevalence of mental disorders is different from many other developing countries where the prevalence accounts to a significant portion of the disease burden 25. Eritrea passing through intense adverse conditions such as wars, one expects a high prevalence of mental disorders in the country which is not the case in this finding. However, this could possibly be explained by under reporting and under diagnosis due to the presence of extremely inadequate number health cadre trained in the field as well as low capacity of health workers to accurately diagnosis mental disorders.

The relatively high frequency of schizophrenia and personality disorders and negligible percentages of drug abuse among the admitted patients is inconsistent to the findings in other LAMIC4 where mood disorders (unipolar disorders) are the single leading neuropsychiatric cause of disease burden and substance abuse account for nearly $4 \%$ of the disease burden. Although no specific investigations were done to determine the causes of the high prevalence rate of Schizophrenia and personality disorders, one can speculate that the protracted conflict situations and associated poverty might have contributed towards this disease burden. However, as in most developing countries, there is low report of substance and drug abuse as compared to the developed countries. This difference can be explained by the limited access and affordability of the drugs and substances to the population.

Thus, in order to address the key bottlenecks and match the internationally accepted standards of mental health services, there is an urgent need for review of the mental health policy, strategic plan of action as well as the management guidelines in Eritrea. These include the allocation of sufficient funds for mental health services, the need for strengthening the human capacity in mental health services including the issue of integration of mental health services with primary health care as supported by intensive relevant training courses in psychiatry, and the promotion of multi-sectoral collaboration. Further studies/research to improve mental health services in line to human resources allocation, organization of mental health services and appropriate financing of mental health services should also be considered.

\section{Acknowledgement:}

This study was financially and technically supported by WHO - HQ and Country Office.

\section{References:}

1) Promoting Mental health: concepts, emerging evidence. Practices summary Report: WHO - 2004;

2) Lopez A. Mathers C, Jamison D, Murray C. - Global Burden of Disease and risk factors. (2006) Washington: Oxford University Press and the World Bank);

3) WHO. Mental Health Atlas (2005) Geneva: WHO

4) Vikram Patel, British Medical Bulletin, doi: 10.193; April 30, 2007: Mental health in low and middle income countries,
5) Ustun TB. Sartorius N. eds. Mental illness in genral health care: an international study, Chicherster, John Wiley and Sons, 1995.

6) Ormel J, VonKorffM, Ustun T, Pini S, Korten A, Oldehinkel T. Common mental disorders and disability across cultures: results from the WHO Collaborative Study on Psychological Problems in General HealthCare.JAMA, 1994,272: 17411748.

7) Patel V, Pereira J, Coutinho L, Fernandes R. Poverty, psychological disorder and disability in primary care attenders in Goa, India. British Journal of Psychiatry, 1998,172: 533-536.

8) Patel V, Abas M, Broadhead J, Tood C, Reeler AP. Depression in developing countries: Lessons from Zimbabwe. British Medical Journal, 2001, 322: 482 - 484.

9) Alarcon R, Aguilar-Gaxiola S. Mental health policy developments in Latin America. Bulletin of the World Health Organization, 2000, 78: 483-490.

10) Gureje O, Alem A; Mental Health policy development in Africa. Bulletin of the World Health Organization, 2000, 78: $475-482$

11) World Psychiatry Association and Society of Psychiatrists of South Africa. Summary report: Meeting on promotion mlof psychiatry and mental health care in Africa. Sun City, Republic of South Africa, 9-10 September 1996.

12) Pantel V., Kleinman A (2003) Poverty and common mental disorders in developing countries. Bulletin of the WHO, 81:609-615,

13) Almedom, Berhe Tesfamichael, Abdu Yacob, Zaid Debretsion, Kidane Tekelhaimanot, Teshome Beyene, Kira Kuhn, Zemui Alemu; Maternal psychosocial wellbeing in Eritrea: application of participatory methods and tools of investigation and analysis in complex emergency settings. Astier M.; Bulletin of the World Health Organization, 2003, 81: 360 - 366

14) de Jong JTVM, Komproe $\mathrm{IH}$, Ommeren MV. Common mental disorders in postconflict settings. Lancet (2003) 361: 2128 - 2130).

15) Shekhar Saxena, Antonio Lora, Mark van Ommeren, Thomas Barrett, Jodi Morris, Benedetto Saraceno: WHO's Assessment Instrument for Mental Health Systems: Collecting Essential Information for Policy and Service Delivery.

16) Primary Health Care Policy and Policy Guidelines, April 1998, Eritrea

17) Mental Health Policy, Plan and Programs, WHO - 2005.

18) Ahmed Okasha, Mental health in Africa: the role of WPA; World Psychiatry 1(1): $32-35$.

19) Migration of Health Workers; Fact Sheet: No. 301, April 2006,

20) Isaac MK, Chandrasekhar CR, Murthy RS. Mental health care by primary care doctors. Bangalore, National Institute of Mental Health and Neuro Sciences, 1994.

21) Schulsinger $F$, Jablensky $A$. The national mental health programme in the United Republic of Tanzania: A report from WHO and DANIDA. Acta Psychiatrica Scandinavica, 1991, 83 (Suppl. 364): 1-132.

22) Qureshi NA, Al-Ghamdy YS, Al-Haddad NS, Abdelgadir MH, Tawfik MH

23) Albert Yeung M.D., Sc.D., a, b, Winnie W. Kung M.S.W., Ph.D.c, Henry Chung M.D.d, Grace Rubenstein B.A.a, Pamela Roffi B.A.a, David Mischoulon M.D., Ph.D.a and Maurizio Fava M.D.a: Integrating psychiatry and primary care improves acceptability to mental health services among Chinese Americans

24) Badger L, Robinson H, Farley T; J. Fam. Pract. 1999 Oct;48(10):813-8. Management of mental disorders in rural primary care: a proposal for integrated psychosocial services. 